\title{
Effect of cooking methods on levels of folates and ascorbic acid in cowpea (Vigna unguiculata L. Walp) from Nairobi, Kenya
}

\author{
Mumbi J. ${ }^{{ }^{*}}$, Wanjau R. ${ }^{1}$, Murungi J. ${ }^{1}$ \\ ${ }^{1^{*}, 1}$ Department of Chemistry, Kenyatta University, P.O Box 43844-0100, Nairobi, Kenya \\ ${ }^{1 *}$ Corresponding Author. Email: jennymumbi0@gmail.com
}

Received: 18 July 2020 / Accepted: 30 November 2020 / Published online: 29th January 2021

\begin{abstract}
Folate (vitamin $B_{9}, 5$-methyltetrahydrofolate) and ascorbic acid (AA) (vitamin C) play a key role in human health and wellbeing. It is greatly established that AA is beneficial in preventing scurvy while folate helps in prevention of neural tube defects and congenital malformations. The main sources of these vitamins are fruits and vegetables especially green leafy vegetables including the African Indigenous Vegetables (AIVs). However, these vegetables are consumed after cooking which leads to loss of the vitamins through oxidation, thermal degradation, and leaching. The study aimed at determining the effect of different cooking methods on the retention of AA and folate in cowpea (Vigna unguiculata L. Walp) as affected by different cooking methods. Folate and AA were determined using high pressure liquid chromatography with ultra UV-visible detection, HPLC-UV after extraction of the vitamins from raw and cooked samples. Analysis of Variance (ANOVA) was used to determine difference in nutrients retention by various cooking methods. Significance was imputed at $\mathrm{p}<0.05$. Raw $V$. unguiculata contained $45.516 \pm 0.649$ $\mathrm{mg} / 100 \mathrm{~g} \mathrm{AA}$ and $91.736 \pm 0.586 \mu \mathrm{g} / 100 \mathrm{~g}$ folate. The cooked samples of the vegetable contained folate ranging from $40.713 \pm 0.081$ to $65.128 \pm 0.007 \mu \mathrm{g} / 100 \mathrm{~g}$ and $\mathrm{AA}$ ranging from $10.719 \pm 0.063$ to $24.181 \pm 0.051 \mathrm{mg} / 100 \mathrm{~g}$ of the edible portion of the vegetable. Cooking the vegetable significantly reduced both folate and AA concentration compared to the raw vegetable samples, $\mathrm{p}<0.05$. Frying raw vegetables with onions and tomatoes was found to retain significant folate and AA than boiling the vegetables, $\mathrm{p}<0.05$. Addition of milk resulted in significant retention of folate and significant loss of AA than boiling, $\mathrm{p}<0.05$. Both lye and sodium bicarbonate significantly reduced folate and AA concentration than boiling, with lye causing
\end{abstract}

significant reduction of both vitamins than sodium bicarbonate $\mathrm{p}<0.05$. It is concluded that cooking reduces folate and AA concentration in cowpea ( $V$. unguiculata $\mathrm{L}$. Walp). Additive such as lye and bicarbonate also reduce the concentration of the vitamins. Cooking cowpea leaves with addition of milk and frying with onion and tomatoes retains more folate than boiling. However, AA is significantly lost in the process than when the vegetable is just boiled.

Keywords: Folate, ascorbic acid, cooking method, retention, cowpea.

\section{INTRODUCTION}

Shortage of macronutrients remain a key focus in public health due to its devastating consequences such as susceptibility to growth inhibition, mental incapacitation, visual disorders, early death, flaunts in birth and vulnerability to infections (Githuku et al., 2012; Botto et al., 1999). These deficiencies are due to inability to access foods rich in vitamins and minerals caused by poverty and unfavorable climatic conditions, overreliance on staple foods and foods that have been highly refined especially in urban areas (Cheruiyot, 2011). Fortification with vitamins and minerals and supplementation are expensive solutions for most Africans, hence there is need to consider alternative sources of vitamins (Cheruiyot, 2011; Wakhanu, 2014) for example African indigenous vegetables (AIVs).

Folate (vitamin $\mathrm{B}_{9}, 5$-methyltetrahydrofolate) and ascorbic acid (AA) (vitamin C) are among the nutrients whose deficiencies lead to devastating outcomes. Spinal bifida and anencephaly are neural tube defects (NTDs) that are 
chiefly caused by folate deficiency (Botto et al., 1999). For every 300,000 pregnancies worldwide one always exhibits NTDs (Botto et al., 1999; McKillop et al., 2002). Githuku et al. (2014) reported that $93 \%$ of 6041 surgeries carried out at Kijabe Mission Hospital in Kenya between 2005 and 2010 were due to spinal bifida. In addition, for every 1000 births in Kenya, $4.6 \%$ present NTDs (Muga et al., 2009) and 800 birth defects resulting from NTDs were reported in a period of 5 years, 2013-2017 (Wafula, 2017). Scurvy is an ailment of the past but it is continually encountered in children with mental or physical disabilities and people with abnormal dietary habits, similarly, the elderly worldwide (Halestrap \& Scheenstra, 2018). Nonetheless, healing and recovery of the patients was realized after intervention with AA (Halestrap \& Scheenstra, 2018). The WHO recommends that $40 \mathrm{mg}$ and $0.4 \mathrm{mg}$ ascorbic acid and folate respectively should be consumed daily by an adult person and women of accouchement age (in case of folic) to prevent scurvy and occurrence of NTDs respectively (Halestrap \& Scheenstra, 2018; Botto et al., 1999; Wafula, 2017; McKillop et al., 2002; Muga, 2009).

Apart from fortified foods and supplements, folates and ascorbic acid can be ingested from foods rich in folates and AA including green leafy vegetables, fruits, legumes and some breakfast cereals. The AIVs are among the vegetables that remain underutilized due to shortage of knowledge on them (Wakhanu, 2014) and their nutrient content can be altered by many factors including post harvesting processes (Cheruiyot, 2011) like cooking (Habwe et al., 2010). Traditionally, these vegetables are cooked in unspecified amounts of water contributing to high nutrient loss (Habwe et al., 2010; Wakhanu, 2014). Additives such as fresh and sour milk, bicarbonate of soda, lye (traditional salt) and common salt are used, yet their effects on levels of folate and AA in the AIVs are unknown. These need to be investigated by quantifying the levels of nutrients with different cooking methods and use of different additives on the AIVs. This study reports effects of traditional cooking methods on levels of folate and AA in cowpea ( $V$. unguiculata L. Walp) and recommends recipes with highest folate and ascorbic acid retention.

\section{MATERIALS AND METHODS}

\section{Research design}

The research was an experimental design where levels of folates (Vitamin $\mathrm{B}_{9}$ ), ascorbic acid and AA (Vitamin C) were analyzed from formulated recipes obtained from cowpea leaves from Githurai market in Nairobi, Kenya.

\section{Chemicals and reagents}

The HPLC grade reagents: acetonitrile and HPLC water used in flashing the equipment were obtained from Merck
Germany. Vitamin standards (5-methyltetrahydrofolate, 5MTHF and L-ascorbic acid), potassium hydrogen carbonate, metaphosphoric acid (MPA) and acetic acid were of analytical grade from Sigma-Aldrich, Germany. Distilled water was used in the experimental procedures.

\section{Preparation of ascorbic acid extraction solution}

Acetic acid, $8 \%$ and MPA $3 \%$ were prepared by dissolving $15.000 \mathrm{~g}$ MPA in $40 \mathrm{~mL}$ acetic acid and $200 \mathrm{~mL}$ distilled water in $500 \mathrm{~mL}$ beaker and pouring the solution into $500 \mathrm{~mL}$ volumetric flask. The beaker was rinsed thrice with distilled water and the contents were poured into the volumetric flask then toped up to the $500 \mathrm{~mL}$ mark with distilled water.

\section{Preparation of folate extraction solution}

A solution of $20 \mathrm{mM} \mathrm{KHCO}_{3}$ was prepared by dissolving $2.002 \mathrm{~g}$ of $\mathrm{KHCO}_{3}$ in $200 \mathrm{~mL}$ distilled water in a $500 \mathrm{~mL}$ beaker and pouring the solution into $1000 \mathrm{~mL}$ volumetric flask. The beaker was rinsed thrice with distilled water and the contents were poured into the volumetric flask then toped up to the $1000 \mathrm{~mL}$ mark with distilled water.

\section{Preparation of standards}

Each standard was prepared separately since analysis of the vitamins were also done separately. $100.000 \mathrm{mg}$ of vitamin C (L-ascorbic acid) standard and $50.000 \mathrm{mg}$ of folate standards (5-methyltetrahydrofolate, 5MTHF) were weighed into $100 \mathrm{~mL}$ beakers and dissolved with $35 \mathrm{~mL}$ of the extraction solutions. The solutions were transferred into $100 \mathrm{~mL}$ volumetric flasks and the beakers rinsed thrice using extraction solutions and the contents poured into the volumetric flasks which were then toped up with the extraction solutions to the $100 \mathrm{~mL}$ marks. The concentrations of the resulting stock solutions were equal to $100 \mathrm{ppm}$. Standards of different concentrations: 10, 20, $50,60,80$ and $100 \mathrm{ppm}$ were prepared by diluting the stock solutions using extraction solution and were used for preparation of calibration curves.

\section{Samples and sample preparation}

Vegetables samples: Cowpea leaves ( $V$. unguiculata) were bought from Githurai market in Nairobi, Kenya between December 2019 and February 2020. The soil conditions under which the vegetables were grown were not considered. The samples were purchased on the morning of the experiment day from different vendors and mixed to uniformity. A total of $6.000 \mathrm{Kg}$ of the vegetable was purchased. The vegetables were bought twice on different days for analysis of each vitamin. On arrival in the laboratory, the fresh and healthy vegetables were mixed and washed immediately under tap water then rinsed with distilled water and excessive water dripped off. 
All procedures were carried out carefully without much exposure to light.

\section{Preparation of lye}

After removing the mature beans seeds, pods were burnt on a hot pan and $200.000 \mathrm{~g}$ of the ash collected was put in a container with holes at the bottom. Distilled water $(500 \mathrm{~mL})$ was poured through the ash a little at a time and filtrate (lye) was collected underneath. This was done according to the modified method described by Wakhanu (2014)

\section{Cooking}

A portion of $100.000 \mathrm{~g}$ of the edible portion of vegetable samples including leaves and young shoots, were used in each of the cooking methods according to modified recipes described by FAO/Government of Kenya (2018a).The vegetables were blanched by immersing in boiling water for 2 minutes while steaming was done for 5 minutes. The cooked samples were then immersed into ice cold water immediately to halt the cooking process. Boiling was done by putting the vegetables in $600 \mathrm{~mL}$ water and boiling for 30 minutes. A $25 \mathrm{~mL}$ aliquot of lye (traditional salt) and $3.000 \mathrm{~g}$ of sodium bicarbonate (baking powder) were added separately in $600 \mathrm{~mL}$ of water and samples boiled for 30 minutes. The same amount of lye and sodium bicarbonate was used in other cooking procedures. The vegetable samples that were boiled then fried were cooked in two continuous processes involving boiling for 20 minutes, discarding the boiling water then frying for 10 minutes. In one case, the vegetables were fried in oil only while in the other case, a mixture oil, onions and tomatoes were used. During frying with oil, onion and tomatoes, the quantity used for each was $5 \mathrm{~mL}, 10.000 \mathrm{~g}$ and 15.000 g respectively. Other vegetable samples were boiled for 20 minutes then boiling water was discarded followed by adding $60 \mathrm{~mL}$ fresh milk and left to cook for further 10 minutes. Some raw samples were fried directly without boiling using $5 \mathrm{~mL}$ oil only or fried in a mixture of $5 \mathrm{~mL}$ oil, $10.000 \mathrm{~g}$ onions and $15.000 \mathrm{~g}$ tomatoes then left to cook for 30 minutes. After every cooking procedure, rapid cooling was done by spreading the cooked sample on an aluminium foil and floating it on ice cold water followed by immediate extraction of either folate or ascorbic acid. Each cooking procedure was done ones and for every sample that was cooked, the vitamin of interest was extracted thrice for analysis.

\section{Extraction of vitamin}

Vitamin $\mathrm{B}_{9}$ was extracted according to the modified procedure describe by Dionex (2010) and McKillop et al. (2002) while Vitamin C was extracted according to the procedure described by Cheruiyot (2011) and Ismail and
Fun (2003). According to the procedures, mortar and pestle were used to grind $10.000 \mathrm{~g}$ of sample then mixed with $50 \mathrm{~mL}$ extraction solution containing: $20 \mathrm{mM} \mathrm{KHCO}_{3}$ (for vitamin $\mathrm{B}_{9}$ extraction) and 3\% Metaphosphoric acid, MPA, and $8 \%$ acetic acid (for vitamin $\mathrm{C}$ extraction). The mixture was then placed in a conical flask wrapped with aluminium foil and agitated at $100 \mathrm{rpm}$ using an orbital shaker for 15 minutes at room temperature. The extract was then filtered using Whatman filter paper No. 42 and transferred to $100 \mathrm{~mL}$ volumetric flask and made to the mark with extraction solution. Further filtration was done by passing through $0.45 \mu \mathrm{l}$ filter membrane followed by immediate analysis to determine concentration of vitamins. All samples were extracted in triplicates.

\section{Identification and quantification of vitamins}

Reverse-phase high pressure liquid chromatography (RPHPLC Shimadzu 20A Kyoto, Japan) consisting of a column (model CTO-10AS VP), a degasser (model DGU-20A5R), an LC pump (model LC-20AD), a UV-Visible diode array detector (model SPD_20A) and an auto sampler (model SIL-20AHT) was used in identification and quantification of Vitamin $\mathrm{C}$ and folates respectively. The samples were separated with a reverse-phase $\mathrm{C}_{18}$ column (Phenomenex $\mathrm{C}_{18}, 250 \times 46 \mathrm{~mm}, 5 \mu \mathrm{m}$ particle size, Luna $5 \mathrm{u}$ ).

Sample separations for AA and folates were done isocratically using $8 \% \mathrm{MPA}$ as the mobile phase for AA at a flow rate of $1.2 \mathrm{~mL} / \mathrm{min}$ as described by Cheruiyot (2011) and $25 \mathrm{mM}$ phosphate buffer ( $\mathrm{pH}$ 3.6) flowing at $0.5 \mathrm{~mL} / \mathrm{min}$ as the mobile phase for folates as described by Dionex (2010). Detection of AA and folate at $254 \mathrm{~nm}$ and $280 \mathrm{~nm}$ respectively was done using UV/Vis detector (Shimadzu UFCL SPD-20A). A $20 \mu \mathrm{L}$ aliquot of standards and samples were injected into the column.

\section{Data analysis}

Composition of nutrients in vegetable samples was determined in triplicates and means computed. The obtained data was analyzed using Statistical Product and Service Solutions software (version 20). Analysis of Variance (ANOVA) was used to determine difference in nutrients retention by various cooking methods. Significance was imputed at $\mathrm{p}$ values of less than 0.05 .

\section{RESULTS}

Vitamin $\mathrm{C}$ and folates were analyzed in raw and cooked $V$. unguiculata. The vitamins were analyzed using HPLC methods to determine their levels. Folate levels were reported in $\mu \mathrm{g} / 100 \mathrm{~g}$ while ascorbic acid levels were reported in $\mathrm{mg} / 100 \mathrm{~g}$ of the vegetables. Percentage retained was also determined. The results obtained in this study are presented in Tables 1 and 2. 


\section{Levels of folates in raw and cooked cowpea (V. unguiculata)}

The mean concentration of folate in raw and cooked cowpea and the percentage retentions with different cooking methods are shown in Table 1. Raw cowpea leaves were found to have a mean concentration of $91.736 \pm 0.586$ $\mu \mathrm{g} / 100 \mathrm{~g}$ folate. Different cooking methods resulted in significant differences in the mean concentration of folates in $V$. unguiculata $(\mathrm{p}<0.05)$. Mean concentration of folate in cooked cowpea leaves ranged from $40.713 \pm 0.081 \mu \mathrm{g} / 100 \mathrm{~g}$ to $65.128 \pm 0.007 \mu \mathrm{g} / 100 \mathrm{~g}$. Blanching and steaming retained significant amounts of folates with steaming retaining $71.00 \%$ while blanching retained $70.31 \%$ of folate that was initially present in the raw sample. Cooking the AIV with lye had the lowest retention of $44.38 \%$ of folate with a concentration of $40.713 \mu \mathrm{g} / 100 \mathrm{~g}$. Boiling V. unguiculata in lye and sodium bicarbonate and boiling in lye then frying with oil only, resulted in significant reduction of folate concentration than boiling the vegetables in water. Nevertheless, boiling the vegetable in water significantly reduced folate concentrations than frying raw vegetables directly. Boiling also caused a significant reduction of folate in cowpea compared to boiling it in sodium bicarbonate or lye then adding milk. There was also a significant loss during boiling in water than boiling in the sodium bicarbonate or lye then fry with onions and tomatoes or boiling in sodium bicarbonate then frying in oil only. Lye significantly reduced folate than sodium bicarbonate in cowpea leaves.

Table 1: Mean concentrations of folate and its retention in cowpea leaves subjected to various cooking treatments.

\begin{tabular}{|c|c|c|c|}
\hline & Sample treatment & $\begin{array}{l}\text { Mean Concentration } \\
\qquad \begin{array}{c}(\mu \mathrm{g} / \mathbf{1 0 0 g}) \pm \mathrm{SE} \\
(\mathrm{n}=\mathbf{3})\end{array}\end{array}$ & $\%$ retention \\
\hline 1 & Raw & $91.736 \pm 0.586^{\mathrm{a}}$ & 100.00 \\
\hline 2 & Steamed & $65.128 \pm 0 . .^{007 b}$ & 71.00 \\
\hline 3 & Blanched & $64.495 \pm 0.142^{\mathrm{c}}$ & 70.31 \\
\hline 4 & Raw-fried (onions+tomatoes) & $61.539 \pm 0.310^{\mathrm{d}}$ & 67.08 \\
\hline 5 & Raw-fried (oil only) & $60.353 \pm 0.019^{\mathrm{e}}$ & 65.79 \\
\hline 6 & Boiled with bicarbonate, then milk added & $56.419 \pm 0.012^{\mathrm{f}}$ & 61.50 \\
\hline 7 & Boiled with lye then milk added & $55.467 \pm 0.055^{\mathrm{g}}$ & 60.46 \\
\hline 8 & Boiled with bicarbonate, then fried & $54.369 \pm 0.347^{\mathrm{h}}$ & 59.27 \\
\hline 9 & (onions+tomatoes) & $53.845 \pm 0.001^{\mathrm{h}}$ & 58.70 \\
\hline 10 & Boiled with lye, then fried (onions+tomatoes) & $50.906 \pm 0.240^{\mathrm{i}}$ & 55.49 \\
\hline 11 & Boiled with bicarbonate, then fried (oil only) & $49.135 \pm 0.045^{\mathrm{j}}$ & 53.56 \\
\hline 12 & Boiled & $45.555 \pm 0.057^{\mathrm{k}}$ & 49.66 \\
\hline 13 & Boiled with lye, then fried (oil only) & $41.277 \pm 0.040^{1}$ & 45.00 \\
\hline \multirow[t]{6}{*}{14} & Boiled with bicarbonate & $40.713 \pm 0.018^{1}$ & 44.38 \\
\hline & Boiled with lye & & \\
\hline & Mean square & $488.927,0.139$ & \\
\hline & df & 13,28 & \\
\hline & F-value & 3515.635 & \\
\hline & P-value & $<0.05$ & \\
\hline
\end{tabular}

Note: Concentration values with superscripts of different letters are significantly different at $p<0.05$ 
Table 2: Mean concentrations of ascorbic acid and its retention in cowpea leaves subjected to various cooking treatments.

\begin{tabular}{llcc}
\hline & Sample treatment & $\begin{array}{c}\text { Mean Concentration } \\
(\mathbf{m g} / \mathbf{1 0 0 g}) \pm \mathbf{S E} \\
(\mathbf{n}=\mathbf{3})\end{array}$ & \% retention \\
& & $45.516 \pm 0.649^{\mathrm{a}}$ & 100.00 \\
\hline $\mathbf{1}$ & Raw & $24.181 \pm 0.051^{\mathrm{b}}$ & 53.13 \\
$\mathbf{2}$ & Steamed & $22.645 \pm 0.258^{\mathrm{c}}$ & 49.75 \\
$\mathbf{3}$ & Blanched & $20.503 \pm 0.234^{\mathrm{d}}$ & 45.05 \\
$\mathbf{4}$ & Raw-fried (onions+tomatoes) & $20.323 \pm 0.046^{\mathrm{d}}$ & 44.65 \\
$\mathbf{5}$ & Boiled & $20.060 \pm 0.031^{\mathrm{d}}$ & 44.07 \\
$\mathbf{6}$ & Raw-fried (oil only) & $19.682 \pm 0.175^{\mathrm{d}}$ & 43.24 \\
$\mathbf{7}$ & Boiled with bicarbonate, then milk added & $16.353 \pm 0.278^{\mathrm{e}}$ & 35.93 \\
$\mathbf{8}$ & Boiled with lye then milk added & $15.542 \pm 0.293^{\mathrm{f}}$ & 34.15 \\
$\mathbf{9}$ & Boiled with bicarbonate, then fried (onions+tomatoes) & $14.056 \pm 0.040 \mathrm{~g}$ & 30.88 \\
$\mathbf{1 0}$ & Boiled with lye, then fried (onions+tomatoes) & $13.127 \pm 0.178^{\mathrm{h}}$ & 28.84 \\
$\mathbf{1 1}$ & Boiled with bicarbonate, then fried (oil only) & $12.371 \pm 0.215^{\mathrm{i}}$ & 27.18 \\
$\mathbf{1 2}$ & Boiled with lye, then fried (oil only) & $11.064 \pm 0.148^{\mathrm{j}}$ & 24.31 \\
$\mathbf{1 3}$ & Boiled with bicarbonate & $10.719 \pm 0.063^{\mathrm{j}}$ & 23.55 \\
$\mathbf{1 4}$ & Boiled with lye & & \\
& & 231.281 & \\
\hline & Mean square & 1273.081 & \\
\hline & df & $<0.05$ & \\
\hline & F-value & & \\
\hline
\end{tabular}

Note: Concentration values with superscripts of different letters are significantly different at $\mathrm{p}<0.05$

\section{DISCUSSION}

The present study investigated the influence of traditional cooking methods on folate and ascorbic acid retention on V. unguiculata.

\section{Folate}

This study found that folate concentration in cowpea leaves was $91.736 \pm 0.586 \mu \mathrm{g} / 100 \mathrm{~g}$ which was not far from the findings by FAO/Government of Kenya (2018b) of $95 \mu \mathrm{g} / 100 \mathrm{~g}$ of edible portions of the vegetable. Therefore, its consumption with staple foods in Kenya should be encouraged. The results showed significant reduction of folate in cowpea leaves during different cooking methods which was in agreement with findings of McKillop et al. (2002) who attributed the loss in western vegetables (spinach and broccoli) to thermal degradation, oxidation and leaching of the vitamin from vegetables into cooking water. Our present results showed that steaming followed by blanching did not cause statistically significant loss of folate but rather resulted in higher retention comparative to other cooking methods. These findings on cowpea leaves (AIVs) were in agreement with findings in analysis of western vegetables like spinach, broccoli and brassica (DeSouza \& Eitenmiller, 1986; McKillop et al., 2002; Lucia et al., 2014). These studies determine 58\% retention in spinach and $91 \%$ in broccoli, each cooked by steam blanching. Vital to note is that these cooking methods (steaming and blanching) had shorter cooking time compared to those used both in current and previous studies.

There was a significant decrease of folate in boiled $V$. unguiculata due to leaching of the vitamin into cooking water. DeSouza and Eitenmiller (1986) reported that water blanching caused higher loss of folate than steam blanching in spinach and broccoli. McKillop et al. (2002) reported that boiling spinach and broccoli led to more folate loss than steaming the vegetable while Delchier et al. (2016) stated that soaking spinach, turnip, cabbage, 
and broccoli caused more folates to be leached into water than that retained in the vegetables. Thus, folate in AIVs is leached into water just like in the western vegetables.

Furthermore, addition oflye and bicarbonate of soda during boiling caused a further loss of folate in $V$. unguiculata. The two additives are characterized by high alkalinity: Sodium bicarbonate has a pH of 8.1 (Haug, 2010), while lye has a pH of 10.8 (Bergeson, 2014) which destroys cellulose in vitamin cells thus increases the instability of 5-methyltetrahydrofolate (Ball, 2006). At temperatures above $40{ }^{\circ} \mathrm{C}$ the stability of 5 -methyltetrahydrofolate is highly reduced (Gazzali et al., 2016). The combination of the high cooking temperature and high alkalinity from lye and sodium bicarbonate resulted in the significant loss of folate in cowpea leaves. This also explains the significant retention observed when raw $V$. unguiculata was fried directly either with oil only or in addition of onions and tomatoes during frying compared to boiling and cooking with lye and sodium bicarbonate. Nonetheless, minimal amount of water was used during the two frying procedure to prevent scorching hence reduced loss of folate through leaching (Ball, 2006; DeSouza \& Eitenmiller, 1986; McKillop et al., 2002; Lucia et al., 2014). Preparation of lye involved burning beans pods at high temperature of above $300{ }^{\circ} \mathrm{C}$ (Wotton et al., 2012) in presence of oxygen. This results in thermal degradation of 5-MTHF since it is denatured at temperatures above $40{ }^{\circ} \mathrm{C}$ (Gazzali et al., 2016) and is also lost through oxidation (Delchier et al., 2014). Therefore, this led to the assumption that the contribution of folate by lye when used as an additive was negligible. On the other hand, no folate was added by sodium bicarbonate into the cooking vegetables since it does not contain folate as an ingredient.

Boiling the vegetable in water only resulted in significant loss of folate than cooking $V$. unguiculata with addition of milk, onions and tomatoes even after boiling with lye and sodium bicarbonate. This was due to addition of the vitamin into the mixture by the additives. Onions and tomatoes contain significant amounts of folate, $25 \mu \mathrm{g} / 100 \mathrm{~g}$ and $15 \mu \mathrm{g} / 100 \mathrm{~g}$ respectively. Milk also contains $6 \mu \mathrm{g} / 100 \mathrm{~g}$ of folate (FAO/Government of Kenya, 2018b; George, 2001). Thus, cooking vegetables with these additives resulted in significant retention of folate, compared to boiling, which was attributed to addition of the vitamin into the vegetables by the additives. Nonetheless, addition of milk in the AIV after cooking with lye or sodium bicarbonate resulted in significantly higher retention of folate, $60-61 \%$ compare to addition of onions and tomatoes, $58-59 \%$. Besides, when the vegetables are boiled in lye and baking powder, folate retention is significantly low at $44-45 \%$. According to Ball (2006), thermal stability of 5-methyltetrahydrofolate is greatly increased in presence of iron (ii), ascorbate and the protein casein. All present in milk by reducing dissolve oxygen hence, reducing the loss of the vitamin through oxidation. The added folate from onions and tomatoes also undergo more oxidation compared to that added by milk which is more stable due to prevailing conditions.

\section{Ascorbic acid}

The present study reported a concentration of $45.516 \pm 0.649$ $\mathrm{mg} / 100 \mathrm{~g}$ of AA present in raw cowpea leaves which was in agreement with (FAO/Government of Kenya, 2018b) of $50 \mathrm{mg} / 100 \mathrm{~g}$. This study also showed that cooking led to significant reduction of AA which is attributed to thermal degradation, leaching and oxidation of the vitamin (Ball, 2006; Imungi \& Potter, 1983; Wakhanu, 2014) during the cooking process. Steaming and blanching $V$. unguiculata retained significant concentration of AA, $53.13 \%$ and $49.75 \%$ respectively compared to boiling, $44.65 \%, \mathrm{p}<0.05$. The findings were comparable to report by Mellova et al. (1996) which showed that vitamin C retention in spinach (western vegetable) decreased with increased water activity since AA is highly soluble in water $33 \mathrm{~g} / 100 \mathrm{~mL}$ at $25^{\circ} \mathrm{C}$ (Ball, 2006).

There was significantly less reduction of AA when fried directly with onions and tomatoes than boiling. This was due reduced water content for leaching of the vitamins (Mellova et al., 1996) and addition of AA from onions and tomatoes. According to Abushita et al. (1997) tomatoes contain 0.22 to $0.48 \mathrm{mg} / \mathrm{g}$ of AA. Vital to note is that when the vegetable was fried in oil only, there was significantly higher loss of AA than boiling. This loss was attributed to high rate of oxidation since the vegetables were exposed to air unlike in boiling where they are completely immersed in water. After oxygen in boiling water is used, the dissolving of more oxygen from air is negligible hence oxidation is reduced (Wakhanu, 2014). The cooking oil used in the current study was sunflower oil which also contains iron and copper, $94 \pm 3.3 \mathrm{ppb}$ and $2 \pm 0.2 \mathrm{ppb}$ respectively (De Leonardis et al., 2000). The addition of these transition metals ions to the AIV during cooking increase the loss of AA due to catalytic oxidation of AA leading to formation of metal-oxygen-ascorbate complexes (Ball, 2006).

Cooking V. unguiculata using lye and sodium bicarbonate reduces AA significantly compared to boiling. Habwe and Walingo (2011) reported an increase in amounts of ionizable iron and copper when cooking vegetables with lye. In the presence of these ions, ascorbic acid undergoes catalytic oxidation to form metal-oxygenascorbate complex (Ball, 2006). At alkaline conditions, cells cellulose structure is denatured, this exposes AA to thermal degradation (Chirambo \& Senga, 2004). Thus, cooking V. unguiculata using lye and sodium bicarbonate 
significantly reduces AA concentrations. Just like folates, $\mathrm{AA}$ is also lost through oxidation and thermal degradation during preparation of lye. At temperatures above $45^{\circ} \mathrm{C}$, AA undergoes thermal degradation and oxidation (Ejoh et al., 2005) thus, the addition of AA from lye to cowpea leaves during cooking was assumed to be negligible. Sodium bicarbonate does not contain AA among the ingredients used in its preparation hence, does not add the vitamin to the cooking vegetables.

Furthermore, the vegetable boiled in lye and milk and sodium bicarbonate and milk significantly reduced AA concentration compared to boiling. Similarly, the samples cooked in lye and sodium bicarbonate then fried with either oil only or oil, onions and tomatoes contained significantly lower AA content than the boiled ones. Milk contains $14 \mathrm{mg} / 100 \mathrm{~g}$ AA while onions and tomatoes contain 13 $\mathrm{mg} / 100 \mathrm{~g}$ and $25 \mathrm{mg} / 100 \mathrm{~g}$ respectively. However, when these additives were added to the vegetables, the AA levels were significantly lowered. These findings were comparable to (Wakhanu, 2014) who attributed these findings to increase in extractable ions of iron and copper from the additives, (milk, lye, tomatoes and oil) leading to oxidation of ascorbic acid and rapid thermal degradation of AA, thus reducing the levels. Cooking the cowpea leaves with lye/sodium bicarbonate and adding the additives did however, lower AA content in the vegetable than boiling in water only. This is because the alkalinity of lye and sodium bicarbonate caused rapid thermal degradation of AA (Ball, 2006).

\section{CONCLUSSION}

Cowpea (Vigna Unguiculata L. Walp) contain relatively high amount of folate and ascorbic and should be recommended for consumption with staple foods. Cooking the vegetable reduces folate and AA concentration significantly mainly through leaching, oxidation and thermal degradation. Steaming and blanching resulted in significant retention of folate and ascorbic acid than boiling cowpea leaves hence should be encouraged. Use of additive such as lye and bicarbonate should be avoided since they result to significant loss of both folate and AA. Cooking cowpea leaves with addition of milk and frying with onion and tomatoes is to be recommended for folate retention than boiling. However, if AA is the vitamin of focus, then boiling the vegetables is a better option than using the mentioned additives.

\section{ACKNOWLEDGEMENTS}

We express our gratitude to Kenyatta University, Department of Chemistry and Department of Food Nutrition and Dietetics where analysis of samples was done, to Elly Makuba for financial support and John
Muniu Gachoya for excellent technical assistance. We are also grateful to Christine Khaenzeli Washiko and Clare Sachini Washiko for assistance in cooking the vegetable samples.

\section{REFERENCES}

Abushita, A. A., Hebshi, E. A., Daood, H. G., \& Biacs, P. A. (1997). Determination of antioxidant vitamins in tomatoes. Food Chemistry, 60(2), 207-212.

Albright, L., Guo, J., \& Arvelo, W. (2014). Assessing the prevalence of Spina bifida and Encephalocele in a Kenyan hospital from 2005-2010: implications for a neural tube defect surveillance system. The Pan African Medical Journal, 18, 60.

Ball, G. F. M. (2006). Vitamins in foods: analysis, bioavailability, and stability. London, Taylor and Francis Group.

Bergeson, T. L. (2014). Use of filtrate from crop residue ash for cooking in rural households in Northern Uganda. Master's Thesis, University of Northern British Columbia.

Botto, L. D., Moore, C. A., Khoury, M. J., \& Erickson, J. D. (1999). Neural-Tube defects. New England Journal of Medicine, 341(20), 1509-1519.

Chirambo, G., \& Senga, E. (2004). Effects of cooking additives on the content of vitamin $\mathrm{C}$ in some vegetables in southern Malawi. Malawi Medical Journal, The Journal of Medical Association of Malawi, 16(1), 17-18.

De Leonardis, A., Macciola, V., \& De Felice, M. (2000). Copper and iron determination in edible vegetable oils by graphite furnace atomic absorption spectrometry after extraction with diluted nitric acid. International Journal of Food Science and Technology, 35(4), 371-375.

Delchier, N., Herbig, A. L., Rychlik, M., \& Renard, C. M. G. C. (2016). Folates in fruits and vegetables: contents, processing, and stability. Comprehensive Reviews in Food Science and Food Safety, 15(3), 506-528.

Delchier, N., Ringling, C., Cuvelier, M. E., Courtois, F., Rychlik, M., \& Renard, C. M. G. C. (2014). Thermal degradation of folates under varying oxygen conditions. Food Chemistry, 165, 85-91.

DeSouza, S. C., \& Eitenmiller, R. R. (1986). Effects of processing and storage on the folate content of spinach and broccoli. Journal of Food Science, 51(3), 626-628.

Ejoh, R. A., Tanya, A. N., Djuikwo, V. N., \& Mbofung, C. M. (2005). Effect of processing and preservation on the iron and vitamin A (total carotenoid) levels of some species of Vernonia. Sciences Des Aliments, 25(3), 185-192.

FAO/Government of Kenya. (2018a). Kenyan food recipe: $A$ recipe book of common mixed dishes with nutrient values. Nairobi, FAO, pp. 349. Retrieved on October, 18, 2019 from http://www.fao.org/3/18897EN/18897en. 
pdf.

FAO/Government of Kenya. (2018b). Kenya food composition tables. Nairobi, pp. 254. Retrieved from http://www.fao.org/3/19120EN/19120en.pdf on October, 16, 2019.

Gazzali, A. M., Lobry, M., Colombeau, L., Acherar, S., Azaïs, H., Mordon, S., Arnoux, P., Baros, F., Vanderesse, R., \& Frochot, C. (2016). Stability of folic acid under several parameters. European Journal of Pharmaceutical Sciences, 93, 419-430.

George, M. (2001). The challenge of culturally competent health care: applications for asthma. Heart \& lung, 30(5), 392-400.

Githuku, J. N., Azofeifa, A., Valencia, D. T., Hamner, H., Amwayi, S., Gura, Z., Omolo, J., Albright, L., Guo, J., \& Arvelo, W. (2014).Assessing the prevalence of Spina bifida and Encephalocele in a Kenyan hospital from 2005-2010: implications for a neural tube defect surveillance system. The Pan African Medical Journal, 18,60 .

Habwe, F. \& Walingo, M. K. (2011). Using food grade lye " omushelekha" in the formulation of health products from commonly consumed African indigenous vegetables and vegetable combinations: Functional foods in health and diseases, 1(5), 189-197.

Habwe, F., Walingo, M. K., \& Onyango, A. (2010). Copper and ascorbic acid content of cooked African Indigenous Vegetables: Presented at conference on International Research on Food Security, Natural Resource Management and Rural Development. EHT Zurich, September 146, 2010.

Halestrap, P., \& Scheenstra, S. (2018). Outbreak of scurvy in Tana River County, Kenya: A case report. African Journal of Primary Health Care \& Family Medicine, 10(1), 1-3.

Haug, C. (2010). Baking powder, baking soda, washing soda, cream of tartar. Retrieved from https://www. essentialstuff.org/2010/09/28/cat/baking-powderbaking-soda-washing-soda-cream-tarta/ on July, 28, 2020.

Imungi, J. K., \& Potter, N. N. (1983). Nutrient contents of raw and cooked cowpea leaves. Journal of Food Science, 48(4), 1252-1254.

Ismail, A., \& Fun, C. S. (2003). Determination of vitamin $\mathrm{C}, \beta$-carotene and riboflavin in five green vegetables organically and conventionally grown. 9(1), 31-39.

Lucia, C. M., Della, Mota, E. R. D. S., \& Montini, T. A. (2014). Folates retention in Brassica vegetables consumed in Brazil after different cooking methods. Archivos LatinoAmaricanos De Nutricion, 64(1), 59-68.

McKillop, D. J., Pentieva, K., Daly, D., McPartlin, J. M., Hughes, J., Strain, J. J., Scott, J. M., \& McNulty, H. (2002). The effect of different cooking methods on folate retention in various foods that are amongst the major contributors to folate intake in the UK diet. British Journal of Nutrition, 88(06), 681.

Mellova, M. A., Giraid, W. D., \& Judy, D. A. (1996). Retention of vitamin $C$, iron and $\beta$-carotene in vegetables prepared using different cooking methods. Journal of Food Quality, 20(1997), 403-418.

Muga, R., Mimah, S. C., \& Juma, P. A. (2009). Congenital malformation among newborns in Kenya. African journal of food agriculture nutrition and development, 9(3), 814-829.

Nicholas, C. (2011). Determination oflevels of some vitamins in Amaranthus hypochondriacus and Amaranthus cruenthus leaves and grains from selected areas of Kenya. Unpublished Masters thesis-Kenyatta University.

Thermo Fischer Scientific, (2017). Determination of water and fat-soluble vitamins by HPLC. Knowledge, creation, diffusion, utilization, pp.1-23. Retrieved March, 4, 2018 from http://www.dionex.com/en-us/webdocs/88784TN89-HPLC-WaterFatSolubleVitamins-27Oct2010LPN2598.pdf.

Wafula, L. (2017). Newborns with birth defects. Daily Nation (November, 1, 2017). Retrieved from https:// www.nation.co.ke/news/Newborns-with-birthdefects/1056-4165758-od04p/ on March, 22, 2018.

Wakhanu, J. A. (2014). Levels of selected antinutrients, vitamins and minerals in African indigenous vegetable recipes in Vihiga County of Western Kenya. Unpublished Masters Thesis-Kenyatta University.

Wotton, B. M., Gould, J. S., McCaw, W. L., Cheney, N. P., \& Taylor, S. W. (2012). Flame temperature and residence time of fires in dry Eucalyptus forest. International Journal of Wildland Fire, 21(3), 270-281. 